Received: Aug 062015 | Accepted after revision: Sept 232015 | First published online: Nov 052015

Conflict of interest: None declared.

\title{
References
}

1 Lönnroth K, Migliori GB, Abubakar I, et al. Towards tuberculosis elimination: an action framework for low-incidence countries. Eur Respir J 2015; 45: 928-952.

2 Matteelli A, Lönnroth K, Getahun H, et al. Numbers needed to treat to prevent tuberculosis. Eur Respir J 2015. [In press DOI: 10.1183/13993003.01179-2015].

3 Falzon D, Gandhi N, Migliori GB, et al. Resistance to fluoroquinolones and second-line injectable drugs: impact on multidrug-resistant TB outcomes. Eur Respir J 2013; 42: 156-168.

4 Migliori GB, Sotgiu G, Gandhi NR, et al. Drug resistance beyond extensively drug-resistant tuberculosis: individual patient data meta-analysis. Eur Respir J 2013; 42: 169-179.

5 Blasi F, Dara M, van der Werf MJ, et al. Supporting TB clinicians managing difficult cases: the ERS/WHO Consilium. Eur Respir J 2013; 41: 491-494.

6 Diel R, Vandeputte J, de Vries G, et al. Costs of tuberculosis disease in the European Union: a systematic analysis and cost calculation. Eur Respir J 2014; 43: 554-565.

7 Sotgiu G, Centis R, D'Ambrosio L, et al. Efficacy, safety and tolerability of linezolid containing regimens in treating MDR-TB and XDR-TB: systematic review and meta-analysis. Eur Respir J 2012; 40: 1430-1442.

8 De Lorenzo S, Alffenaar JW, Sotgiu G, et al. Efficacy and safety of meropenem-clavulanate added to linezolid-containing regimens in the treatment of MDR-/XDR-TB. Eur Respir J 2013; 41: 1386-1392.

9 Tiberi S, D'Ambrosio L, De Lorenzo S, et al. Ertapenem in the treatment of multidrug-resistant tuberculosis: first clinical experience. Eur Respir J 2016; 47: 333-336.

10 Esposito S, D'Ambrosio L, Tadolini M, et al. ERS/WHO Tuberculosis Consilium assistance with extensively drug-resistant tuberculosis management in a child: case study of compassionate delamanid use. Eur Respir J 2014; 44: 811-815.

11 Falzon D, Jaramillo E, Schünemann HJ, et al. WHO guidelines for the programmatic management of drug-resistant tuberculosis: 2011 update. Eur Respir J 2011; 38: 516-528.

12 Chambers HF, Turner J, Schecter GF, et al. Imipenem for treatment of tuberculosis in mice and humans. Antimicrob Agents Chemother 2005; 49: 2816-2821.

13 Tiberi S, De Lorenzo S, Centis R, et al. Bedaquiline in MDR/XDR-TB cases: first experience on compassionate use. Eur Respir J 2014; 43: 289-292.

14 Matteelli A, D’Ambrosio L, Centis R, et al. Compassionate and optimum use of new tuberculosis drugs. Lancet Infect Dis 2015; 15: 1131-1132.

15 Migliori GB, Lienhardt C, Weyer K, et al. Ensuring rational introduction and responsible use of new TB tools: outcome of an ERS multisector consultation. Eur Respir J 2014; 44: 1412-1417.

\section{Tuberculosis in Germany: a declining trend coming to an end?}

To the Editor:

In the context of the newly adopted World Health Organization (WHO) End TB strategy, an action framework towards tuberculosis (TB) elimination in low incidence countries has been launched $[1,2]$. Its aim is to reach pre-elimination of TB (less than 10 cases per one million inhabitants) by 2035 and TB elimination (less than one case per one million inhabitants) by 2050. Germany belongs to the addressed countries and territories with a TB incidence lower than 10 cases per 100000 inhabitants. To reach these targets, Germany would have to have an annual reduction in the TB incidence of about $10 \%[1,2]$.

However, electronic TB notification data available for 2001 through 2014 indicate an end of the declining trend for Germany (figure 1): case numbers and notification rates in the past 2 years exceeded the levels of 2012, reaching $4488 \mathrm{~TB}$ cases and 5.6 cases per 100000 inhabitants in 2014 [3]. This observation is supported by more in-depth analyses.

First, we investigated the 5-year TB trend in terms of average percentage changes in case notification rates as suggested by the WHO [4] and the European Centre for Disease Prevention and Control (ECDC) [5]. We observed an average increase of $0.9 \%$ per year over the period from 2010 through 2014, while all previous 5-year spans showed decreases (figure 1).

Secondly, we assessed whether the $6.3 \%$ increase in TB notification rate for 2014 compared to 2012 was statistically significant using the z-test to compare two proportions (5\% level of significance; two-sided). 


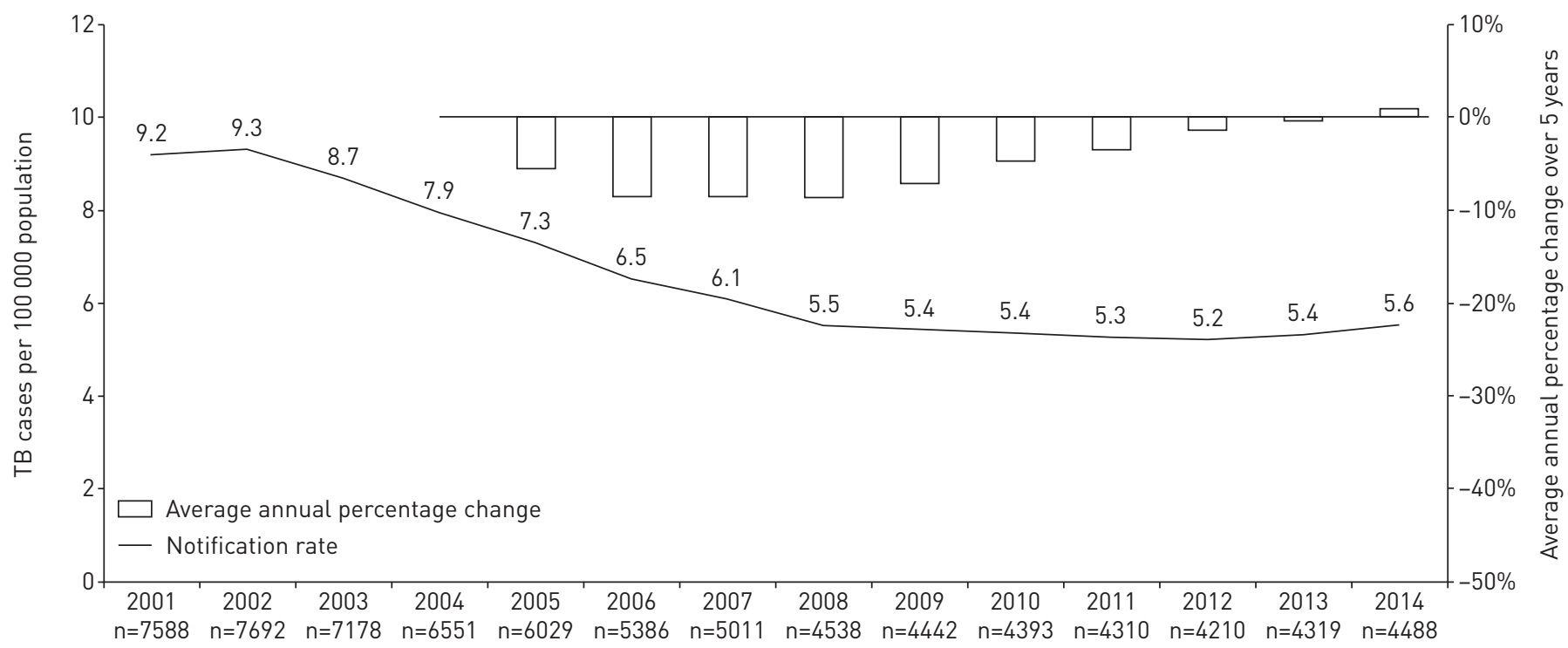

FIGURE 1 Trend in tuberculosis (TB) case notification rate and average annual percentage changes over 5 years, Germany, $2001-2014$.

The difference was significant $(\mathrm{p}=0.005)$. However, the $3.9 \%$ and $2.3 \%$ increases between 2014 and 2013 ( $\mathrm{p}=0.072)$ or 2013 and 2012 ( $\mathrm{p}=0.298)$, respectively, were not significant.

So, just at the beginning of the "countdown" of the End TB Strategy, the downward trend in the TB notification rate is coming to an end in Germany.

How can this be explained? Theoretically, rising case numbers can either result from artefacts in notification data, from increased case detection or reporting, or by an actual increase in TB cases.

The communicable disease surveillance system in Germany is well established on a legal basis [6]. Since 2001, the TB case definition and data collection procedures have remained in general unchanged. The 2011 census in Germany has led to a downward correction of the population denominator since 2012 [7]. This did not markedly impact on the results. Cases may be possibly notified twice when patients, mainly those identified by entry screening at admission into a community facility, move to another district within Germany. However, duplicate search and sensitivity analysis suggest that this may not reverse the observed trend (data not shown).

With regard to case detection and reporting, no regulatory or programmatic changes in active case finding or screening approach have been introduced in Germany in recent years. There has been no change of diagnosis algorithms, except for the inclusion of interferon- $\gamma$ release assays in the diagnostic of latent tuberculosis infection (LTBI) [8].

Assuming an actual increase of TB case numbers, different scenarios may drive it: 1) ongoing domestic spread of TB in Germany; 2) reactivation of LTBI in the native population who has acquired the infection in the past; or 3) reactivation of LTBI in inhabitants who have acquired the infection in another country of origin with commonly higher TB burden; as well as 4) entry of individuals into the country with existing (diagnosed or undiagnosed) active TB. These scenarios require different actions in TB prevention and control.

Information gained from TB surveillance in Germany indicates the existence but no increase in domestic spread (scenario 1): sputum smear microscopy, a marker for infectiousness, was positive in $33 \%$ of pulmonary TB cases. Around $3.7 \%$ of patients per year were epidemiologically linked and allocated to a cluster (as of March 1 of the following year). The proportion of paediatric patients ( $<15$ years of age) born in Germany, who can be considered as "recipients" of ongoing spread, was in average $2.5 \%$ in the observation period (1.6\% in 2014). None of these indicators showed recent increases.

Scenarios 2 and 3 cannot be assessed due to the lack of systematically collected data on pre-existing LTBI and major risk factors for progression, including the use of biologicals, comorbidities or social determinants. However, we observed a decrease in case numbers in the population aged 60 years and over. This is only observed in the German-born population (scenario 2) but not in the foreign-born population, which could indicate a relevant role of scenario 3 .

Regarding scenario 4, some information is collected by the surveillance variable "reasons for diagnosing active TB", i.e. cases identified at admission into a community facility for asylum seekers, refugees or late repatriates on the basis of section 36 of the Protection Against Infection Act [6]. Here, in 2014, the highest 
proportion of $11 \%$ (419/3843) cases with available information) since the beginning of data collection was found (2001-2014 average: 4\%). This observation is consistent with demographic statistics: they reveal a rise in net immigration to Germany [7,9], including an eight-fold increase in initial applications for asylum since 2008 with 173072 new applications in 2014 [9]. Numbers for 2015 are even higher, with 274923 new applications registered through January to September [9].

From 2001 through 2014, the proportion of TB patients born outside of Germany has increased from $42 \%$ to $63 \%[10]$; however, there are no data on time of immigration, which would allow differentiating between scenario 3 and 4 .

Altogether, available data suggest that TB case numbers are currently rather influenced by a changing demographic context (migration and mobility) while there is no indication for increased, nor markedly decreased, transmission within Germany in a context of continued within-country TB control efforts. Similar observations have been made previously in the UK [11].

TB surveillance in Germany might be increasingly measured against its capacity to describe trends in key affected subgroups, to disentangle the outlined scenarios, and to monitor progress in TB control and prevention in each area. The systematic collection of information on the TB patients' time of immigration (as piloted [12]), and chains of transmission by an integrated molecular surveillance (piloted, for multiand extensively drug-resistant TB pursued under the umbrella of the ECDC [13]) are priority areas.

TB control is, overall, well-established in Germany [14]. Priority areas for further strengthening TB control in line with the End TB strategy include, for example, special needs of migrants and cross-border issues (area 3) and prevention (area 4) [2, 15].

A declining TB trend remains the ultimate goal, yet against the background of a changing demographic situation, this goal may presently not serve as an operational objective. Current action needs to be focused on early and comprehensive active TB case finding (even if initially further increasing case numbers) followed by optimum $\mathrm{TB}$ patient care and management for all, which is an essential investment to avert TB cases in the longer term.

@ERSpublications

Coinciding with the launch of the End TB Strategy, tuberculosis case numbers are re-increasing in Germany http://ow.ly/Tj2f0

Lena Fiebig, Barbara Hauer, Bonita Brodhun, Doris Altmann and Walter Haas

Dept for Infectious Disease Epidemiology, Robert Koch Institute, Berlin, Germany.

Correspondence: L. Fiebig, Dept for Infectious Disease Epidemiology, Robert Koch Institute, Respiratory Infections Unit, Seestr. 10, 13353 Berlin, Germany. E-mail: FiebigL@rki.de

Received: Aug 252015 | Accepted after revision: Oct 092015 | First published online: Oct 222015

Conflict of interest: None declared.

Acknowledgements: We thank all contributors to the surveillance of tuberculosis in Germany, in particular the local public health offices and state health departments. All investigated data were anonymous and collected within the legal framework of the Protection Against Infection Act.

\section{References}

1 World Health Organization. Towards Tuberculosis Elimination: an Action Framework for Low-incidence Countries. Geneva, World Health Organization, 2004. WHO/HTM/TB/2014.13. Available from: http://apps.who. int/iris/bitstream/10665/132231/1/9789241507707_eng.pdf Date last accessed: July 23, 2015.

2 Lönnroth K, Migliori GB, Abubakar I, et al. Towards tuberculosis elimination: an action framework for low-incidence countries. Eur Respir J 2015; 45: 928-952.

3 Robert Koch Institute. Survstat@rki 2.0 - Web-based Query on Data Reported Under the German 'Protection against Infection Act’. Berlin, Robert Koch Institute. https://survstat.rki.de/default.aspx Date last accessed: July 23, 2015.

4 World Health Organization. Compendium of Indicators for Monitoring and Evaluating National Tuberculosis Programmes. Geneva, World Health Organization, 2004. WHO/HTM/TB/2004.344. Available from: www.who.int/ tb/publications/tb_compendium_of_indicators/en/ Date last accessed: July 23, 2015.

5 European Centre for Disease Prevention and Control. Progressing Towards TB Elimination. A Follow-up to the Framework Action Plan to Fight Tuberculosis in the European Union. Stockholm, European Centre for Disease Prevention and Control, 2010. Available from: http://ecdc.europa.eu/en/publications/Publications/101111_SPR_ Progressing_towards_TB_elimination.pdf Date last accessed: July 3, 2015.

6 Protection Against Infection Act [Gesetz zur Verhütung und Bekämpfung von Infektionskrankheiten beim Menschen (Infektionsschutzgesetz - IfSG)]. 2000. http://bundesrecht.juris.de/ifsg [German] Unofficial translation: www.rki.de/EN/Content/Prevention/Inf_Dis_Surveillance/inf_dis_surveillance_node_en.html Date last accessed: July 23, 2015.

7 Federal Statistical Office (Destatis). Bevölkerung und Erwerbstätigkeit - Wanderungen. Wiesbaden, Federal Statistical Office, 2014. www.destatis.de/DE/Publikationen/Thematisch/Bevoelkerung/Wanderungen/Wanderungen 2010120137004.pdf?_blob=publicationFile [German]. Date last accessed: July 3, 2015. 
Diel R, Loytved G, Nienhaus A, et al. New recommendations for contact tracing in tuberculosis. German Central Committee against Tuberculosis [Neue Empfehlungen für die Umgebungsuntersuchung bei Tuberkulose. Deutsches Zentralkomitee zur Bekämpfung der Tuberkulos] Pneumologie 2011; 65: 359-378.

9 Federal Office for Migration and Refugees. Aktuelle Zahlen zu Asyl. Nürnberg, Germany: Federal Office for Migration and Refugees, October 7, 2015. Available from. https://www.bamf.de/SharedDocs/Anlagen/DE/Downloads/Infothek/ Statistik/Asyl/statistik-anlage-teil-4-aktuelle-zahlen-zu-asyl.html Date last accessed: October 12, 2015.

10 Robert Koch Institute. Reports on the Epidemiology of Tuberculosis in Germany [Berichte zur Epidemiologie der Tuberkulose in Deutschland]. Berlin, Germany, Robert Koch Institute. www.rki.de/tuberkulose Date last accessed: September 22, 2015.

11 Zenner D, Zumla A, Gill P, et al. Reversing the tide of the UK tuberculosis epidemic. Lancet 2013; 382: 1311-1312.

12 Marx FM, Fiebig L, Hauer B, et al. Higher rate of tuberculosis in second generation migrants compared to native residents in a metropolitan setting in western Europe. PLoS One 2015; 10: e0119693.

13 De Beer JL, Ködmön C, van der Werf MJ, et al. the ECDC MDR-TB molecular surveillance project participants. Molecular surveillance of multi- and extensively drug-resistant tuberculosis transmission in the European Union from 2003 to 2011. Euro Surveill 2014; 19: pii=20742.

14 Hauer B, Fiebig L, Brodhun B, et al. Tuberculosis surveillance and control in Germany - an application of the Berlin Declaration Monitoring and Evaluation Framework. Eur J Microbiol Immunol 2012; 2: $287-291$.

15 D'Ambrosio L, Dara M, et al. Tuberculosis elimination: theory and practice in Europe. Eur Respir J 2014; 43: 1410-1420.

\title{
Recruitment challenges for clinical trials with novel regimens for drug-resistant tuberculosis
}

\author{
To the Editor:
}

Drug resistance is a growing public health problem. The World Health Organization reported an estimated 480000 new cases of multidrug-resistant tuberculosis (MDR-TB) worldwide in 2013, of which 9\% were estimated to be extensively drug-resistant (XDR)-TB. The prevalence of HIV co-infection among TB patients in the African region is high [1]. In South Africa, 65\% of TB patients tested for HIV are HIV-positive [2].

Treatment for drug-resistant (DR)-TB is long, costly and arduous with consistently poor outcomes and high default rates [2-5]. New treatment options are slowly emerging through clinical trials, while evidence for existing agents is often scarce [6]. Recruitment of suitable subjects for clinical trials has proven challenging at our research site [7,8]. This study aimed to estimate the proportion of potentially eligible subjects among the population with DR-TB in our area and the most frequent reasons of nonparticipation in ongoing clinical trials for DR-TB.

We used the example of two recently completed trials (www.clinicaltrials.gov: NCT00910871 and NCT00449644) to create a set of commonly applicable demographic, social, medical and TB-related criteria for a trial in DR-TB (table 1). Demographic and social criteria aimed to identify cooperative adults likely to comply with rigid visit schedules and long-term follow-up typical of a phase 3 trial. Medical criteria were to exclude subjects at increased risk of adverse events and those with conditions that could interfere with the treatment outcome end-points. HIV-positive subjects not on antiretroviral treatment were allowed (CD4 cut-off at the time was $<250$ cells. $\mathrm{mL}^{-1}$ ). TB-related criteria required documented infection with Mycobacterium tuberculosis with resistance to isoniazid (INH) and rifampin (RIF), but excluded higher-grade resistance if known, and treatment-naive status for the current episode.

At the time of data collection all patients diagnosed with DR-TB in the Cape Town Metropole were referred to a regional centre at Brooklyn Chest Hospital $(\mathrm{BCH})$ in Cape Town to be registered and evaluated for treatment. Resistance testing in the state laboratory for INH and RIF was done with line probe assays and phenotypical testing at that time. GeneXpert and line probe assays for agents other than INH and RIF were not yet available. A Task Applied Science research team (TASK) was situated on the premises of $\mathrm{BCH}$. A single TASK physician (S. Siwendu) retrospectively evaluated the case files of each referral to $\mathrm{BCH}$ for DR-TB for a 3-month period against the criteria in table 1. If a subject seemed not to qualify, the reasons were noted from the records. Individuals were not contacted for additional 